\title{
La sinagoga Mayor de Segovia y sus propiedades urbanas a comienzos del siglo XV
}

\author{
Bonifacio Bartolomé Herrero*
}

Archivo de la Catedral de Segovia

La sinagoga Mayor de Segovia fue construida a fines del siglo XIII o entrado ya el siglo XIV. A comienzos del siglo XV fue tomada a los judíos y consagrada como iglesia bajo la advocación del Corpus Christi, siendo entregada en 1421 su posesión a la abadía agustina de Santa María de Párraces. En el presente trabajo el autor recopila las noticias conocidas de esta sinagoga, se analiza la significación religiosa, social y económica de la iglesia de Corpus Christi desde su consagración hasta la expulsión de los judíos, y se estudian seis contratos de alquiler (fechados entre 1424 y 1478) que permiten reconstruir el conjunto de bienes inmuebles que habían pertenecido a la antigua sinagoga.

Palabras Clave: Sinagoga; judería; siglos XIV-XV; Castilla; Segovia; iglesia de Corpus Christi.

The Grand Synagogue of Segovia and its Urban Properties at the Beginning of THE $15^{\text {TH }}$ Century.- The Grand Synagogue of Segovia was built at the end of $13^{\text {th }}$ century or in the early $14^{\text {th }}$. It was taken from the Jews at the beginning of the $15^{\text {th }}$ century, being consecrated as a church dedicated to the Corpus Christi, and in 1421 it was given to the Augustinian abbey of Santa Maria de Parraces. In this article, the author provides a compilation of the known data concerning this synagogue, as well as with an analysis of the religious, social and economic meaning of the Corpus Christi church, from its dedication until the end of expulsion of the Jews. He also studies six tenancy agreements that has allowed him to reconstruct the real estate that once belonged to the synagogue.

KeYwords: Synagogue; Juderia; $14^{\text {th }}-15^{\text {th }}$ Centuries; Castile; Segovia; Corpus Christi's Church.

\footnotetext{
bbartolome@hotmail.com
} 
Durante la Baja Edad Media, la ciudad de Segovia albergó una destacada comunidad judía ${ }^{1}$. Esta aljama contó a lo largo de su historia con un total de cinco sinagogas ${ }^{2}$. Dos de ellas, la Vieja y la Mayor, objeto esta última del presente estudio, fueron expropiadas a los judíos en los convulsos inicios del siglo XV, mientras que una tercera, la sinagoga de Burgos, desaparece de la documentación por esas mismas fechas, en 1418. Las dos restantes, la nueva sinagoga Mayor y la sinagoga del Campo, fueron construidas a lo largo del siglo XV, y mantuvieron su función hasta la expulsión de $1492^{3}$.

\section{LA SINAGOGA MAYOR}

La ausencia de testimonios documentales o epigráficos motiva que se desconozcan el momento y las circunstancias en los que la comunidad judía segoviana edificó su sinagoga Mayor ${ }^{4}$. Los investigadores que han analizado arquitectónica y artísticamente esta sinagoga han coincidido en señalar su similitud con la denominada de Santa María la Blanca de Toledo, pero no mantienen igual unanimidad a la hora de datar su edificación. Por citar tan solo dos de las propuestas más recientes, Ruiz Hernando supone que la sinagoga segoviana «fue levantada a finales del XIII en su totalidad», mientras que Ruiz Souza opina por su parte que «fue construida avanzado ya el siglo XIV» ${ }^{5}$. En todo caso, como se puede apreciar, el

\footnotetext{
${ }^{1}$ Una aproximación a la historia de los judíos segovianos, en mi «La aljama judía de Segovia en la plena edad media (1215-1412)», en El patrimonio hebreo en la España medieval (Córdoba 2004), 239-256.

${ }^{2}$ Para la judería segoviana y sus sinagogas resultan esenciales los estudios de J. A. Ruiz Hernando, El barrio de la aljama hebrea de la ciudad de Segovia (Segovia 1980) [en adelante, El barrio de la aljama hebrea (1980)]; IDEM, El barrio de la aljama hebrea de Segovia (Segovia 2008) [en adelante, El barrio de la aljama hebrea (2008)]; también, J. L. LaCave, Juderías y sinagogas españolas (Madrid 1992), 205-213.

3 A este respecto puede consultarse, Y. Moreno Koch, «La venta de sinagogas en Segovia al tiempo de la expulsión», Sefarad 46 (1986), 345-351.

${ }^{4}$ La antigua sinagoga y actual iglesia de Corpus Christi carece aún de un estudio monográfico que aborde con profundidad y rigor su pasado histórico-artístico. Destaco las páginas dedicadas por José Antonio Ruiz Hernando a este edificio en su reciente trabajo sobre la judería segoviana como una de las referencias más completa y actualizada sobre el mismo, en su El barrio de la aljama hebrea (2008), 112-141.

${ }^{5}$ Ruiz Hernando, El barrio de la aljama hebrea (2008), 116. J. C. Ruiz Souza, «Sinagogas sefardíes monumentales en el contexto de la arquitectura medieval hispana», en Memoria de Sefarad (Madrid 2002), 225-239: 233.
} 
marco cronológico que actualmente proponen los especialistas acota en buena medida el debate sobre la fecha de construcción del edificio.

La documentación, por su parte, no ha aportado hasta el momento ninguna información significativa sobre la sinagoga. De hecho, las únicas fuentes que proporcionan algún dato al respecto son los registros de la mayordomía de pitanzas de la catedral de Segovia, que recogían cada año los arrendamientos de las propiedades capitulares. En estos registros se agrupaban los inmuebles por barrios y se localizaban asociándolos a hitos urbanísticos de referencia como iglesias, calles o corrales. En este contexto es precisamente en el que aparece citada la sinagoga Mayor, como una simple referencia para ubicar unas casas situadas frente a su fachada norte. Estas menciones, aunque ciertamente escuetas, resultan sin embargo del mayor interés por ser hasta el momento las únicas noticias existentes de la sinagoga Mayor.

La primera mención conocida se encuentra en el más antiguo de los registros conservados, el correspondiente al ejercicio económico 1372-73. Los siguientes cuadernos, que recogen los datos relativos a los ejercicios $1389-90^{7}, 1390-91^{8}, 1392-93^{9}, 1397-98$ o $1398-99^{10}$ y i $1409-10 ?^{11}$, siguen incluyendo la referencia a la sinagoga Mayor. La serie de los registros de pitanzas se interrumpe hacia 1410 y se vuelve a reanudar con el cuaderno correspondiente al ejercicio 1419-20. En éste la referencia a la sinagoga

${ }^{6}$ «Ytem, y luego otras casas enfruente de la sinagoga Mayor, tienelas tienelas [sic] Iohan Sanches de Vriviesca, canonigo, rynde C maravedis», Archivo de la Catedral de Segovia [en adelante, ACS], C-416, fol. 2v, cf. F. FitA, «La judería de Segovia. Documentos inéditos», BRAH 9 (1886), 270-293, 344-389 y 460-468; y 10 (1887), 75-79: 292 (doc. 3), 349-350 (doc. 5), data erróneamente en 1410 el registro. Ruiz Hernando, El barrio de la aljama hebrea (1980), 48; IDEM, Historia del urbanismo en la ciudad de Segovia del siglo XII al XIX (Segovia 1982), vol. II, 266; El barrio de la aljama hebrea (2008), 188 (doc. 1).

${ }^{7}$ «Delante la sygnoga Mayor ay tres casas. La primera que sale a la calle tienela un iudyo, LXV maravedis. La otra primera del corral tienela Abrahem, moro, por XXV maravedis. Item, la otra tienela Hamete, moro, por çinco annos, cada anno por XXX maravedis», ACS, C-417, fol. 2v, cf. FITA, «La judería de Segovia», 292 (doc. 3) y 345 (doc. 4). Ruiz Hernando, El barrio de la aljama hebrea (1980), 50.

${ }^{8}$ «Delante la sinoga Mayor ay tres casas. La primera que s[ale a la ca]lle tienela Juda Alarod, LXV maravedis. La otra primera del corral tienela Habraem, moro, XXV maravedis. La otra tienela Hamet, moro, XXX maravedis», ACS, C-418, fol. 2v. Ni Fita ni Ruiz Hernando recogen esta referencia. 
se sustituyó por otra a la eglesia nueva, esto es, a la de Corpus Christi, lo que permite afirmar que en septiembre de 1420 la conversión de la sinagoga en una iglesia cristiana era ya un hecho consumado ${ }^{12}$.

El propio edificio apenas ofrece información sobre su pasado judío, pues en 1899 la iglesia resultó destruida casi por completo en un incendio $^{13}$. Tampoco se conservan restos, ni siquiera noticias, de inscripciones en hebreo asociadas al edificio. Algunas fotografías y dibujos realizados antes de la ruina de la iglesia permiten conocer su estado en el siglo XIX,

\footnotetext{
${ }^{9}$ «Enfruente de la sinoga Mayor ay tres casas. La primera que sale a la calle rinde sesenta e çinco maravedis, tienela Yuda Alarod; LXV maravedis. La otra primera del corral rinde veynte çinco maravedis, tienela Abraem, moro; XXV maravedis. La otra segunda rinde treynta maravedis, tienela Hamet, moro; XXX maravedis», ACS, C-419, fol. 2v, cf. RuIz Hernando, El barrio de la aljama hebrea (1980), 52; IDEM, El barrio de la aljama hebrea (2008), 191 (doc. 2).

10 «Enfruente de la signoga ay tres casas. La una tienela donna Clara por L maravedis. La otra tienela Hamed, moro, por XXV maravedis. La otra segunda tienela Abrahen, moro, por XXX maravedis. Las casas a La Solana do solia morar donna Fatima tienelas don Yuçaf, moro, por CXXX maravedis», ACS, C-420, fol. 9r. FITA, «La judería de Segovia», 349 (doc. 5); data el registro en 1400. Ruiz Hernando, El barrio de la aljama hebrea (1980), 53; lo data «hacia 1400». Este cuaderno recoge la celebración de doce aniversarios por el obispo segoviano Afonso Correia fallecido el 15 de mayo de 1397 (fol. 16r), e incluye una anotación que indica que el mayordomo de las pitanzas, el racionero Gómez Fernández, rindió cuentas de su gestión el 27 de marzo de 1400 (fol. 47r). Ambos datos implican que el registro sólo puede corresponder a los años administrativos 139798 ó 1398-99. Atendiendo a la anotación referente a Gómez Fernández, en el siglo XVI el cuaderno fue fechado erróneamente como correspondiente a 1400.

${ }^{11}$ «Enfrente de la sinoga Mayor. La primera casa tienela Yhuda Falcon [...] La segunda dentro tienela Clara [...] La terçera tienela don Abrahen Chivo [...]», cf. Ruiz Hernando, El barrio de la aljama hebrea (1980), 55, que data el registro en 1410. El autor consultó este registro, junto a los demás, en el Archivo de la Catedral de Segovia, pero actualmente está ilocalizable. Sigo la datación del manuscrito indicada por Ruiz Hernando que, pienso, debe corresponder al año administrativo 1409-10.

12 «Otra casa enfruente de la eglesia nueva tienela Antona Ferrandes por [tachado: sesenta maravedis] setenta maravedis», ACS, C-422, fol. 6r, cf. FITA, «La judería de Segovia», 292 (doc. 3), y 350 (doc. 5). Ruiz Hernando, El barrio de la aljama hebrea (1980), 57; IDEM, El barrio de la aljama hebrea (2008), 194 (doc. 3). No hay duda de que esta eglesia nueva es la de Corpus Christi, pues en el registro de 1422-23 ya aparece citada como tal: «Otra casa enfruente de Corpus Christi tyenela Antona Ferrandes por sesenta maravedis, LX maravedis», ACS, C-424, fol. 4v.

${ }^{13}$ J. M. Castellarnau, «La sinagoga Mayor de Segovia», BRAH 35 (1899), 319330.
} 
cuando todavía mantenía mucho de su fábrica original. A este respecto, el testimonio gráfico más completo de la antigua sinagoga es la litografía realizada por José Acevedo, sobre un dibujo de José María Avrial y Flores, para la colección Monumentos Arquitectónicos de España $a^{14}$. La lámina, de gran formato, muestra un fragmento de la arquería superior, sendos capiteles, una sección longitudinal de la iglesia y la planta de la misma (figura 1).

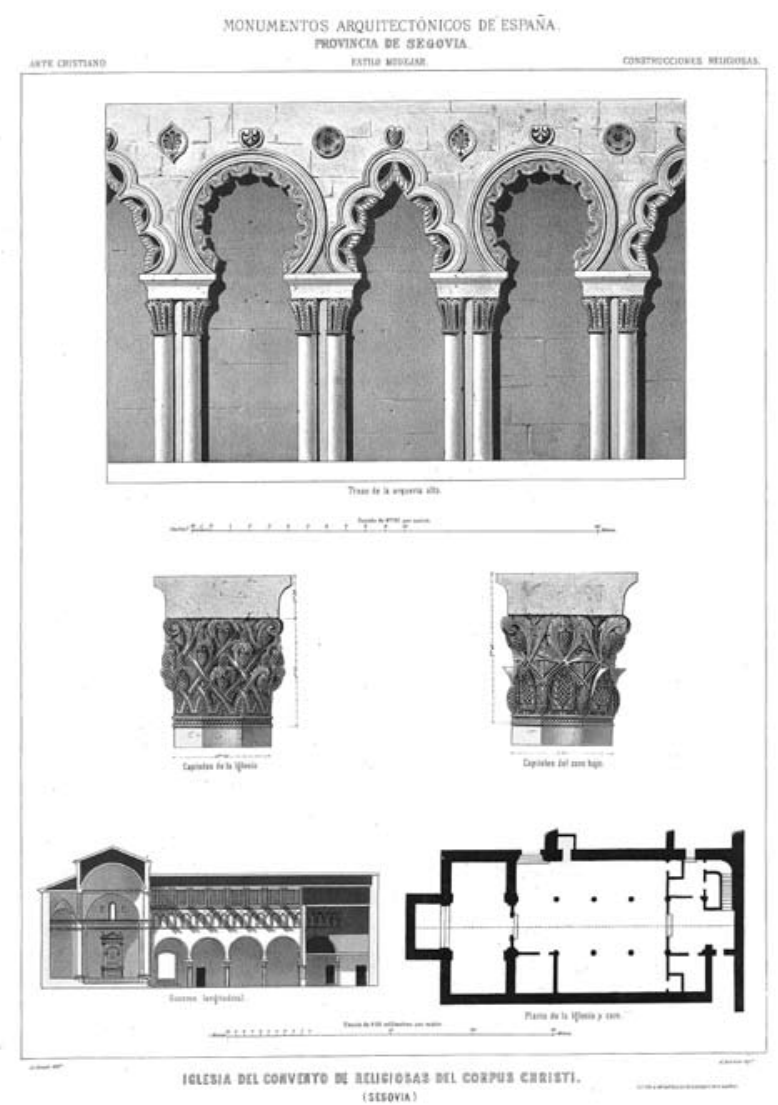

FIgURA 1: Monumentos Arquitectónicos de España. Provincia de Segovia. Iglesia del convento de religiosas del Corpus Christi (Segovia). Litografía de José Acevedo, a partir de un dibujo de José María Avrial y Flores (1860).

\footnotetext{
${ }^{14}$ J. A. Ruiz Hernando, Monumentos Arquitectónicos de España. Iglesias parroquiales de Segovia (Madrid 2008), 57-61 (dibujo 11).
} 


\section{LA EXPROPIACIÓN DE LA SINAGOGA MAYOR Y SU CONSAGRACIÓN COMO IGLESIA}

La pérdida por parte de la comunidad judía segoviana de su sinagoga Mayor se produjo en un contexto de fuerte presión hacia los judíos, que tuvo una incidencia particular en la propia ciudad de Segovia ${ }^{15}$.

En 1412 se promulgó mediante la Provisión de Valladolid, el apartamiento de judíos en barrios propios separados de los cristianos. En Segovia, el concejo situó la judería intramuros en unos terrenos pertenecientes al convento mercedario de Santa María de la Merced. Las autoridades municipales llevaron a cabo esta intervención sin compensar a los frailes, lo que provocó la lógica protesta de éstos. Los mercedarios apelaron entonces a la Corona y solicitaron que, a cambio, se les entregara una sinagoga situada próxima al convento, donde establecerían «un hospital en que se acojan los pobres». Los tutores del rey aceptaron la reclamación, donándoles de este modo

la dicha sinoga, para que la ayades agora e para siempre jamas, con todas sus entradas e salidas e rentas e pertenencias quantas la dicha sinoga avia e aver devia en qualquier manera ante que los dichos judios fuesen apartados ${ }^{16}$.

Por estas mismas fechas encontramos los dos últimos testimonios conocidos de «la sinoga que disen de Burgos» situada en la céntrica parroquia de San Miguel: uno de 1410, y poco después, en 1418, otro relativo «a una casa pequenna de la dicha yglesia [catedral] que esta junta con la signoga de Burgos» ${ }^{17}$.

En cuanto a la sinagoga Mayor, el franciscano fray Alonso de Espina ofrece en su Fortalitium fidei un relato conocido con las circunstancias en las que se produjo su consagración como iglesia ${ }^{18}$. La narración de

\footnotetext{
${ }^{15}$ Bartolomé Herrero, «La aljama judía de Segovia», 243-246.

${ }^{16}$ ACS, B-360, fols. 85r-86v (16-X-1412, Valladolid; copia de 1629 a partir de una confirmación de 1413). Sobre el hospital ubicado en la antigua sinagoga, cf. M. LóPEz DíEZ, «Las artes en el siglo XV: el mecenazgo de los Arias Dávila», en A. GaLindo García (ed.), Segovia en el siglo XV. Arias Dávila: obispo y mecenas (Salamanca 1998), 279-284.

${ }^{17}$ Ruiz Hernando, El barrio de la aljama hebrea (2008), 100-101.

${ }^{18}$ La obra, cuya redacción se inició en 1458, tuvo éxito inmediato en la Península y en el conjunto de Occidente, y la edición princeps fue realizada en Estrasburgo por Johann Mentelin en fecha no posterior a 1471 (British Library, Incunabula Short Title Catalogue, ISTC núm. ia00539000).
} 
los hechos ha sido objeto desde antiguo de controversia, y resulta difícilmente asumible en su redacción literal ${ }^{19}$. Puesto que aquí sólo pretendo incidir en la cronología expuesta por el franciscano en su relato, ofrezco un resumen de los elementos esenciales del mismo para situar de un modo general los acontecimientos, remitiendo al texto original para cualquier análisis detallado de su contenido ${ }^{20}$.

En esencia, fray Alonso relata cómo durante la minoría de Juan II unos judíos segovianos habían comprado del sacristán de la iglesia de San Facundo una forma consagrada para profanarla ${ }^{21}$. Tras llevarla a su sinagoga, intentaron echarla a un caldero con agua hirviendo, sin lograr su propósito porque la forma permaneció suspendida en el aire ${ }^{22}$. Temerosos de que el milagro se hiciera público, los judíos acordaron entregar la forma al prior del monasterio dominico segoviano de Santa Cruz. Éste, pasados unos días, denunció los hechos al obispo Juan Vázquez, que a su vez informó a Catalina de Lancaster, madre y tutora de Juan II, que se encontraba en aquel momento en la ciudad. Los acusados fueron detenidos y sometidos a tormento, y entre ellos se encontraría Mayr Alguadex, médico del difunto Enrique III, que declaró en los interrogatorios haber asesinado a este monarca. Los reos fueron declarados culpables, condenados a muerte y ejecutados con ejemplaridad, mientras que la sinagoga donde habían ocurrido los hechos fue consagrada como iglesia ${ }^{23}$. El franciscano continúa su relato indicando que como el obispo quería seguir

\footnotetext{
${ }^{19}$ La valoración detallada del texto excede los límites del presente trabajo. Para un análisis de los postulados del franciscano, cf. S. J. McMichael, Was Jesus of Nazareth the Messiah?: Alphonso de Espina's argument against the Jews in the Fortalitium fidei (c. 1464) (Atlanta 1994).

${ }^{20}$ He consultado el relato en la edición de Lyon de 1511, fol. 223. Este texto fue publicado por Fita, «La judería de Segovia», 354-357 (doc. 6).

${ }^{21}$ «Undecimum mirabile accidit in ciuitate Segebiensi [sic] anno Domini MCCCCLV regnante domino Iohanne in tenera etate sub tutrice matre sua domina Katherina Castelle regina», Espina, Fortalitium, fol. 223.

${ }^{22}$ «Iudeus ergo ille sacramentum illud accipiens et suis immundis manibus pertractans ad synagogam cum aliis suis complicibus perduxerunt et in bullientem aquam sepe proiicientes in altum eleuabatur ante oculos eorum», Espina, Fortalitium, fol. 223.

${ }^{23}$ «Synagoga vero ubi accidit facta fuit ecclesia et vocatus Corpus Christi, ubi omni anno tota ciuitas in memoriam supra dicti miraculi in die Corporis Christi cum solenni processione conuenit et fit ibi sermo ad populum», EspinA, Fortalitium, fol. 223.
} 
investigando, los judíos sobornaron a su cocinero para que le envenenara. Descubierta la conjura, cocinero y judíos implicados fueron ejecutados, mientras que otros judíos tuvieron que huir de la ciudad. Fray Alonso cierra la narración indicando que conoció los hechos de boca del agustino Martín de Córdoba, a quien a su vez se los había contado el dominico fray Juan de Canalejas, testigo presencial ${ }^{24}$.

Conforme al relato del franciscano, los sucesos de Corpus se produjeron «anno Domini MCCCCLV regnante domino Iohanne in tenera etate sub tutrice matre sua domina Katherina Castelle regina», esto es, $1455^{25}$. Esta referencia contiene un error evidente, pues ese año corresponde al reinado de Enrique IV y no a la minoría de edad de su padre, minoría que había discurrido entre la muerte de Enrique III, el 25 de diciembre de 1406 y la proclamación de su mayoría de edad con catorce años en marzo de 1419.

En su narración, Espina menciona por su nombre a siete personas. Cuatro de ellos son personajes históricos de los que se puede aportar una cronología bastante precisa: el rey Juan II; su madre, la reina Catalina de Lancaster; el obispo segoviano Juan Vázquez, cuyo largo episcopado se extendió entre 1398 y hasta su muerte en 1437; y Mayr Alguadex, «rab de la Corte» y uno de los médicos de Enrique III. En el relato aparecen además mencionados el agustino Martín de Córdoba, el dominico fray Juan de Canalejas y un niño llamado «Spinartio».

De entre los intentos por corregir el error de datación de Espina quiero destacar las dos propuestas que hasta la fecha han sido seguidas por la mayoría de los autores. La primera es la del historiador segoviano Diego de Colmenares, que en el siglo XVII indicaba que al relato del franciscano «le han contestado nuestros historiadores y aunque varían en el tiempo es cierto que sucedió este año 1410 y, según entendemos, en el mes de setienbre. Y assí consta de papeles y tablas de aquella casa y tenplo que has-

\footnotetext{
${ }^{24} \ll$ Hec sepe a pluribus audiui, sed specialiter mihi narrauit reuerendus magister Martinus Cordubensis, ordinis Sancti Augustini, qui asseruit quod sic narrauerat sibi realiter accidisse frater Iohannis de Canaleyas, ordinis predicatorum, qui presens fuit cum iudei apportauerunt corpus Domini cum predicto priori et cum supradicta omnia acciderunt», EspINA, Fortalitium, fol. 223.

${ }^{25}$ Véase nota 21.
} 
ta hoi se nonbra Corpus Christi» ${ }^{26}$. Los papeles y la tabla que Colmenares menciona como argumento de autoridad son muy tardíos y no resisten un mínimo análisis crítico. El escrito es una crónica de la ciudad de Segovia realizada en 1551 por el abogado Garci Ruiz de Castro, que simplemente resumió el relato de Espina e inició el mismo en 1410 sin aportar ninguna explicación a esta cronología ${ }^{27}$. El panel, por su parte, sabemos que se encontraba expuesto en la iglesia de Corpus en 1601 y exhibía un texto basado también en el de fray Alonso de Espina ${ }^{28}$. En segundo lugar, y ya en el siglo XIX, Fita enfocó la cuestión como un mero error del redactor o del impresor, considerando que se debía leer MCCCCXV, esto es, $1415^{29}$.

Como ya se ha visto, los registros de la mayordomía de pitanzas de la catedral muestran que hacia 1410 la sinagoga Mayor seguía siendo tal y que en 1420 ya era una iglesia cristiana ${ }^{30}$. En el cuaderno correspondiente al ejercicio 1419-20, que recoge las cuentas hasta el 31 de agosto de 1420, se habla simplemente de la eglesia nueva, sin señalar advocación alguna $^{31}$. Este detalle, sobre el que ha llamado la atención Ruiz Hernando, sugiere que la consagración se habría podido producir en fechas muy cercanas a las de la redacción del registro ${ }^{32}$. De hecho, hay que hacer notar

\footnotetext{
${ }^{26}$ D. DE Colmenares, Historia de la insigne ciudad de Segovia y compendio de las historias de Castilla (Segovia 1637), XXVIII-VIII, 325.

${ }^{27}$ «Año de 1410 en esta çiudad de Segovia, siendo obispo della don Joan de Tordesillas de buena memoria, un judio médico [...]», ACS, B-369, fol. 15r. El texto completo en J. A. Ruz Hernando, Garci Ruiz de Castro. Comentario sobre la primera y segunda población de Segovia (Segovia 1988), 25. La aceptación de esta fecha por Colmenares en ACS, B-252, fol. $12 \mathrm{v}$.

${ }^{28}$ ACS, B-252, fols. 10r y 12v. El texto completo del panel en Ruiz Hernando, El barrio de la aljama hebrea (2008), 226-228 (doc. 23).

${ }^{29}$ «La corrección más obvia, pues corrección ha de haber, es MCCCCXV (1415)», cf. FITA, «La judería de Segovia», 354, nota 7 (doc. 6).

${ }^{30}$ Véanse las notas 11 y 12. Las actas del cabildo de la catedral de Segovia, otra posible fuente de información, no aportan ningún dato sobre la fecha de la expropiación. Para el período comprendido entre 1407 y 1421 sólo se conservan registros correspondientes a los años 1410 a 1415 y éstos no contienen ninguna referencia a la sinagoga Mayor o a los sucesos de Corpus, ACS, C-1-4 y C-1-5.

${ }^{31}$ ACS, C-422, fol. 6r. Esta denominación, eglesia nueva, se repite en el siguiente registro conservado, el correspondiente al ejercicio 1421-22 (ACS, C-423, fol. 5v) pero desaparece en el siguiente, de 1422-23, donde figura ya Corpus Christi (ACS, C-424, fol. 4v).

32 «Iglesia tan reciente, fijémonos, que aún carece de advocación», cf. RuIz HeRnANDO, El barrio de la aljama hebrea (2008), 112. Sin embargo hay que matizar esta circunstancia, pues la referencia en los registros a la iglesia nueva se repite todavía en 1422, cuando ya
} 
que hasta el 25 de noviembre de 1421 no se encuentra la primera mención documentada de la iglesia con la advocación de Corpus Christi ${ }^{33}$.

En definitiva, a la luz de los datos conocidos, resulta imposible establecer con precisión el momento en el que se produjo la expropiación de la sinagoga Mayor. Como se ha visto, el único relato existente de los hechos sitúa el acontecimiento durante la minoría de Juan II, mientras que la documentación conservada sólo permite afirmar que el suceso se produjo en cualquier caso antes de 1420.

El período que transcurrió entre la expropiación y la anexión de la iglesia a la abadía agustina de Santa María de Párraces permanece en la más absoluta oscuridad. Tan solo cabe indicar que la misma expropiación debió dar paso a un período de incertidumbre sobre el futuro destino del edificio. Si se contempló en algún momento el derribo de la sinagoga o su reforma substancial, el hecho es que esas iniciativas nunca se llevaron a efecto. Sólo se puede afirmar con seguridad que fue en estos momentos cuando se produjo su consagración como iglesia ${ }^{34}$.

El saturado panorama eclesiástico de la ciudad de Segovia a comienzos del siglo XV hace pensar que la iglesia de Corpus debió convertirse muy pronto en un problema para las autoridades religiosas, pues el nuevo templo no podía tener un fácil acomodo en el contexto urbano. En efecto, además de la catedral, Segovia tenía en aquellos momentos una extensa red parroquial integrada por quince iglesias intramuros y similar número fuera del recinto amurallado, y acogía también ocho monasterios y conventos, cinco masculinos y tres femeninos. Además, la ciudad albergaba otras iglesias, capillas y ermitas diseminadas por el núcleo urbano y sus arrabales.

La creación de una nueva parroquia en una zona del solar urbano bien cubierto de ellas sólo se hubiera podido llevar a cabo modificando una estructura fijada cuando menos desde mediados del siglo XIII. Además,

consta documentalmente que la advocación de la iglesia era la de Corpus Christi (véanse las notas 31 y 33 ).

${ }^{33}$ Archivo General de Palacio [en adelante, AGP], Patronatos, San Lorenzo, caja 49, exp. 38 .

${ }^{34}$ Como refleja claramente el documento de anexión a Párraces, la sinagoga ya había sido consagrada como iglesia bajo la advocación del Corpus Christi antes de su entrega a la comunidad agustina, pues la abadía recibió la posesión de «la eglesia nueva de Corpore Christi que es en la çibdat de la dicha Segovia, la qual fue signoga de los judios», AGP, Patronatos, San Lorenzo, caja 49, exp. 38. 
esta fundación se habría de efectuar restando feligreses, y con ello rentas, a las parroquias más cercanas, las de San Miguel y San Martín, con los conflictos que ello hubiera supuesto. Otra posibilidad consistía en la anexión de Corpus Christi a cualquiera de los templos ya existentes en la ciudad, opción que tenía el grave inconveniente de suponer un agravio para las instituciones no favorecidas con tal distinción. Por último, existe constancia de que el obispo Juan Vázquez consideró la posibilidad de establecer un hospital en la antigua sinagoga, como ya había ocurrido en el caso de la sinagoga Vieja, pero el prelado desestimó finalmente esta posibilidad, quizá por la carencia de recursos económicos.

\section{LA IGLESIA DE CORPUS CHRISTI Y LA ABADÍA DE SANTA MARÍA DE PÁRRACES (1421-1571)}

La resolución adoptada finalmente por el obispo de Segovia fue la de anexionar Corpus Christi a la abadía agustina de Párraces. Esta iniciativa tiene todos los visos de haber sido adoptada tras haberse valorado cuidadosamente la cuestión, pues consiguió resolver de modo definitivo y estable la situación anómala planteada en la ciudad por la existencia no planificada de la nueva iglesia, al tiempo que consiguió obviar los inconvenientes señalados más arriba. La sensación que trasmite la cesión del templo tal y como se produjo es que fue una solución meditada y eficaz a un problema inesperado ${ }^{35}$. La anexión de la iglesia a Párraces se produjo además en un momento de especial cercanía y colaboración entre autoridad episcopal y abadía, por lo que resulta probable que fuera consecuencia de un acuerdo previo entre el prelado y el abad agustino ${ }^{36}$.

\footnotetext{
${ }^{35} \mathrm{Si}$ esto fuera realmente así, cabría pensar en los sucesos de Corpus como en un fenómeno espontáneo y tumultuoso que sorprendió a las autoridades civiles y eclesiásticas y les obligó a actuar al hilo de los acontecimientos. Además, para comprender mejor los hechos acontecidos en Segovia resulta obligado insertarlos en el panorama general de la época, en el contexto más concreto de la recepción de la Constitución Apostólica Etsi doctores gentium de Benedicto XIII, que en 1415 instaba a que sólo se permitiera la existencia de una sinagoga por población, cf. J. RIERA I SANS, Els poders públics i les sinagogues. Segles XIII-XV (Girona 2006), 103-111.

${ }^{36}$ «Las anexiones más importantes se produjeron en un breve lapso de tiempo; entre los años 1421 y 1423 el obispo de Segovia aneja a Párraces la iglesia de Corpus Christi, el monasterio de San Pedro de las Dueñas de Río Moros y el beneficio de Muñico. Las relaciones entre la abadía y su fundadora atravesaban entonces una etapa particularmente
} 
Así pues, el 25 de noviembre de 1421 Juan Vázquez anexionó a la abadía

la eglesia nueva de Corpore Christi que es en la çibdat de la dicha Segovia, la qual fue signoga de los judios, con todas las cosas, casas e solares que oy en dia le pertenesçen e pertenesçer deven en qualquier manera, con todas sus entradas e salidas e corrales, sobrados altos e baxos, qualesquier que sean, enfiestos o derribados, que a la dicha eglesia pertenescan o pertenesçer devan asi de fecho como de derecho $^{37}$.

Como ya se ha adelantado, la anexión incluyó una interesante reserva, pues el prelado mantuvo la posibilidad, que finalmente nunca hizo efectiva, de fundar un hospital

en la dicha eglesia o en qualquier de sus casas [...] dando doctaçion e sustentaçion conpetente para el, quedando la carga e cuydado de la dicha ospitalidat

en manos de la abadía ${ }^{38}$. Los dos participantes en la operación resultaron francamente beneficiados con la misma. El prelado no perdió totalmente su autoridad sobre el templo, ya que se reservó «nuestra pontifical jurisdiçion, visitaçion e correçion e nuestra devida reverençia ${ }^{39}$, mientras que la abadía consolidó sin ningún coste por su parte la modesta pero prestigiosa presencia que mantenía desde hacía tres siglos en la sede de la diócesis ${ }^{40}$.

fraternal. El abad don Juan era al mismo tiempo provisor y vicario general del obispado, lo que contribuía a dirigir hacia Párraces esta sucesión de dádivas», cf. E. GAVILÁN, El dominio de Párraces en el siglo XV. Un estudio sobre la realidad feudal (Zamora 1986), 82.

${ }^{37}$ El documento original («una carta [...] escripta en papel [...] e sellada en las espaldas de çera bermeja» fechado en 25-XI-1421, Turégano) se ha perdido y su contenido se conserva en un traslado realizado en Segovia el 4 de noviembre de 1438, AGP, Patronatos, San Lorenzo, caja 49, exp. 38. Ofrezco transcripción del texto en apéndice.

${ }^{38}$ Las necesidades asistenciales y sanitarias de la ciudad eran atendidas en esos momentos por tres hospitales, el regido por los trinitarios del monasterio de Santa María de Rocamador, el de Sancti Spiritus, y el administrado por los mercedarios del convento de Santa María de la Merced (véase nota 16). A esta labor había que sumar la desarrollada por la catedral de Segovia a través de su mayordomía de pobres.

${ }^{39}$ AGP, Patronatos, San Lorenzo, caja 49, exp. 38.

${ }^{40}$ La abadía de Párraces había sido fundada a mediados del siglo XII por canónigos procedentes de la catedral de Segovia y desde aquellos tiempos poseía la iglesia segoviana 
No hay constancia de que se produjera ninguna protesta por la anexión cuando ésta se llevó a efecto, pero alguna irregularidad debió producirse en torno a la misma. En efecto, en noviembre de 1438, un año después de la muerte del obispo Juan Vázquez, el abad de Párraces, don Diego, solicitó el traslado del documento de donación con la intención de utilizarlo «asi en la corte de nuestro sennor el papa, como en la corte de nuestro sennor el rey, como antel sennor obispo de Segovia» ${ }^{41}$. Algunas dudas debía tener la abadía respecto a sus derechos de propiedad sobre la iglesia cuando tuvo que hacer valer los mismos tras el fallecimiento del prelado que diecisiete años antes se la había entregado ${ }^{42}$. En este contexto hay que situar precisamente la confirmación de la anexión realizada en 1440 de un modo conjunto por el sucesor de Juan Vázquez en la mitra segoviana, el dominico fray Lope Barrientos, y la catedral de Segovia, que puso fin a cualquier conflicto existente sobre el particular ${ }^{43}$. Tal y como se declaraba en el documento, la donación se había efectuado en 1421 sin el consentimiento de la institución capitular. Esta circunstancia lleva a considerar que la catedral segoviana tuvo que adquirir algún derecho sobre la sinagoga tras su expropiación, quizá en aplicación de la legislación de la época, derecho que en todo caso fue conculcado por el obispo ${ }^{44}$.

de San Blas, situada extramuros en el actual barrio de San Marcos, cf. GAVILÁN, El dominio de Párraces, 69-76.

${ }^{41}$ AGP, Patronatos, San Lorenzo, caja 49, exp. 38 (4-XI-1438, Segovia).

${ }^{42}$ Esta problemática no se ceñía a una sola propiedad. En 1442 la abadía de Párraces perdió la posesión del monasterio de San Pedro de las Dueñas que también había recibido del obispo Juan Vázquez, en esta ocasión en 1422, un año después de la anexión de Corpus, B. Velasco BAyón, «Las órdenes religiosas en el pontificado de Arias Dávila», en Galindo García (ed.), Segovia en el siglo xv, 323-336: 328.

${ }^{43}$ A mediados del siglo XVII este documento, fechado el 23 de diciembre de 1440, se conservaba todavía entre los papeles de Párraces «en el cajón veinte, en el número segundo» (ANóNImo, «La abadía de Párraces (1646)», Estudios Segovianos 13, 1961, 185-186) pero actualmente no se encuentra en el Archivo General de Palacio, donde recalaron los documentos de la abadía. La confirmación de la anexión tampoco se encuentra en el Archivo de la Catedral de Segovia, donde además no se conservan las actas capitulares correspondientes al año 1440, que podrían incluir alguna referencia a la reclamación de los capitulares. Por último, tampoco hay noticia de este escurridizo documento en el Archivo Diocesano de Segovia.

${ }^{44}$ Aunque no sea el mismo caso que nos ocupa, en las Partidas (VII.24.4) se indica que la sinagoga que fuera construida o reformada fuera de las condiciones establecidas, «debenla perder los judios et seer de la eglesia mayor del lugar do la ficiesen». 
Durante el período que transcurre entre la expropiación de la sinagoga Mayor y la expulsión de los judíos en 1492, la iglesia de Corpus Christi se convirtió en varias ocasiones en escenario de tensiones entre cristianos y judíos. Al mismo tiempo, podemos suponer que la tradición de realizar anualmente el día de Corpus Christi una solemne procesión hasta el templo, donde se predicaba luego un sermón público, debió convertirse también en un motivo de fricciones con la antigua sinagoga como telón de fondo ${ }^{45}$.

La puerta de acceso al templo supone el primer aspecto conflictivo del que tenemos constancia. La sinagoga Mayor no tenía una entrada directa desde la calle, sino que se ingresaba a ella a través de un patio. La primera mención a la entrada del templo se encuentra en 1424, cuando la abadía de Párraces alquiló a Ferrán Arias una casa situada «çerca de la puerta de la dicha iglesia» ${ }^{46}$. En 1478 se citan frente a la fachada norte el «patin e corral de la dicha yglesia de Corpus Christi» ${ }^{47}$. Las profundas reformas sufridas por el edificio a lo largo del tiempo no permiten identificar con seguridad dónde se encontraba, una vez atravesado el patio, la puerta de ingreso a la sala de oración. A la vista de los datos conocidos, Ruiz Hernando supone que ese acceso se encontraba en la citada fachada norte ${ }^{48}$.

El año 1477 la abadía autorizó a sus procuradores a realizar un trueque para que la puerta de entrada al recinto de Corpus Christi se trasladara al solar situado entre las casas del boticario Juan de Segovia y rabí Moisés Abenmayor, «donde viene mejor por ser christiandad» ${ }^{49}$. Así pues, el le-

\footnotetext{
${ }^{45}$ Véase la nota 23 . Es posible que esta procesión estuviera en el origen de la «Catorcena», fiesta local que surgió probablemente en la Edad Moderna. La conmemoración anual en recuerdo de los sucesos de Corpus, que todavía se celebra, la realizan catorce parroquias de la ciudad. Cada año y por turno rotativo una de las parroquias se encarga de organizar los actos.

${ }^{46}$ AGP, Patronatos, San Lorenzo, leg. 85-2.

${ }^{47}$ AGP, Patronatos, San Lorenzo, leg. 85-1 (contrato de Mayr de Vidas), fol. 8v.

48 «Todo aboga pues a favor de la puerta al N, abierta a un patín que se prolongaba en el actual regularizado por Odriozola después del incendio», Ruzz Hernando, El barrio de la aljama hebrea (2008), 129.

49 «Otrosy para trocar e canbiar un suelo de la dicha casa de Corpus Christi que ha por linderos, de la una parte casas de rabi Mose, e de la otra parte casas de Juan de Segovia, boticario, donde se avia de poner la puerta de la dicha casa de Corpus Christi, con qualquier persona o personas que conpraren la dicha casa del dicho Juan de Segovia, para que en ella se passe e pongua la dicha puerta de la entrada de la dicha casa de Corpus
} 
vantamiento del arco gótico de piedra caliza que todavía hoy da acceso al patio de la iglesia habría que situarlo en este contexto aunque, como señala Ruiz Hernando, «sus formas un tanto toscas remiten más bien a una arquitectura de principios de siglo que no a la del final» ${ }^{50}$ (figura 2).

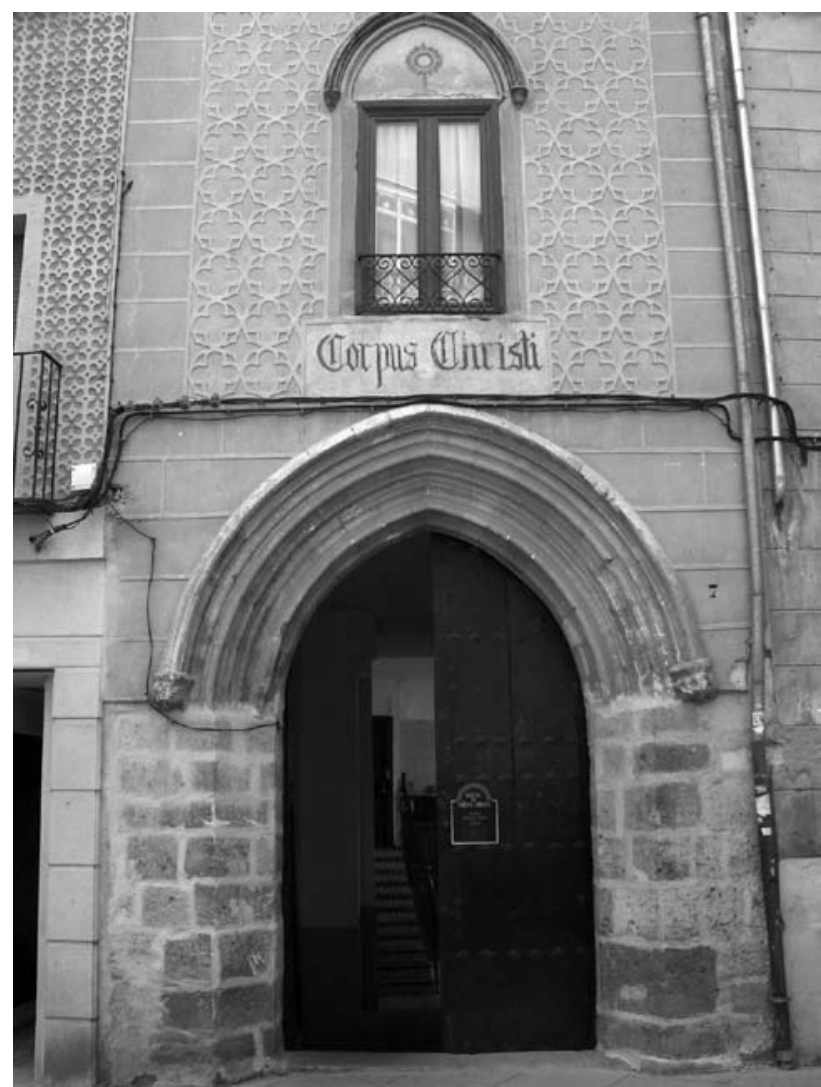

Figura 2: Puerta de acceso al patio de la iglesia de Corpus Christi (hacia 1477).

Christi donde viene mejor por ser christiandad», AGP, Patronatos, San Lorenzo, leg. 85-1 (contrato de Mayr de Vidas), fol. 3v.

${ }^{50}$ Ruiz Hernando, El barrio de la aljama hebrea (2008), 125-126. A la vista de esta valoración, podría considerarse la posibilidad de que hacia 1477 se hubiera trasladado no sólo el lugar de acceso al patio, sino físicamente la puerta que daba acceso al mismo. ¿Puerta levantada quizá cuando se produjo la expropiación? Esta hipótesis permitiría explicar el relativo arcaísmo del actual arco de entrada. 
La conflictividad en torno a la iglesia de Corpus se reavivó en 1481, cuando se delimita el barrio de la judería en cumplimiento de la ordenanza establecida en las Cortes celebradas el año anterior en Toledo. La nueva judería ocupaba una superficie mucho mayor que la del recinto apartado de 1412 y su límite oriental se situó precisamente en la iglesia de Corpus Christi. Este hecho no provocó en sí mismo ningún problema, pero produjo una circunstancia que, dado el clima social reinante, fue aprovechada para reavivar las brasas de un fuego que, por lo que podemos comprobar, nunca se había apagado del todo: la antigua entrada al patio de la iglesia quedó integrada, por unos pocos metros, dentro de la judería.

En efecto, cuando el 29 de octubre de 1481 el delegado regio Rodrigo Álvarez Maldonado supervisó el establecimiento de la judería, dispuso «quel primero sitio de la dicha juderia de la dicha çibdad e sus arravales, que fuese e sea acerca de la yglesia de Corpus Christe donde esta un arco de cal e de ladrillo» ${ }^{51}$. Este arco apoyaba uno de sus extremos en «una pared de la casa de Hayme, sastre, que esta acerca de la yglesia de Corpus Christe» y asentaba el otro en «la casa de Davi Tasarte». Rodrigo Álvarez ordenó también que se cerrasen las ventanas «que estan fasya la dicha yglesia [...] por manera que non se pueda parar a ellas pero que puedan tener luses». Los datos señalados permiten situar esta primera puerta del barrio judío adentrándose unos pocos metros en la calle de la Judería Vieja desde la plaza de Corpus Christi, concretamente frente a la fachada norte de la iglesia entre los actuales números 20 y 25 de la calle.

La prudencia y la sensatez que habían mostrado los canónigos de Párraces en 1477 al impulsar el cambio de ubicación del acceso al patio para evitar roces innecesarios entre cristianos y judíos, contrasta llamativamente con la actitud que adoptaron tan solo siete años después en un contexto, cierto es, de abierta hostilidad colectiva hacia los judíos de la ciudad.

En efecto, en 1485 la aljama de judíos de Segovia denunciaba a los reyes que el acceso al patio de la iglesia de Corpus que se había cerrado hacia 1477 y había quedado dentro de la judería en 1481 había sido abierto de nuevo con gran perjuicio para los vecinos judíos. Además, la aljama exponía que sobre la puerta de entrada al patio, situada a escasos metros de la anterior pero fuera de la judería, se había colocado un crucifijo con la evidente intención de provocar a los judíos que entraban o salían de su

\footnotetext{
${ }^{51}$ FITA, «La judería de Segovia», 277-278 (doc. 1).
} 
barrio. Dado el interés de este conflicto, recojo a continuación la amplia exposición de motivos realizada por los Reyes Católicos en el documento en el que atendieron la reclamación:

Sepades que Jaco Cachopo, en nombre e como procurador del aljama de los judios de la çibdad de Segovia, nos fiso relaçion por su petiçion, que ante nos en el nuestro Consejo presento, diziendo que la dicha aljama e judios de la dicha çibdad de Segovia estando como estan apartados en los lugares e çercuytos que [en blanco] Maldonado por nuestro mandado les dio por juderia, et que agora nuevamente, non lo podiendo nin deviendo faser de derecho segund leyes et hordenamientos destos nuestros reynos, dis que los canonigos de Parrases que tienen la iglesia de Corpus Christi, que es en la dicha çibdad çerca de la dicha juderia, han avierto e mandado abrir e faser una puerta por un corral que es de la dicha iglesia que sale dentro en la dicha juderia e limite e çercuyto della que asy les fue dado, lo qual dis que es en perjuizio de la dicha juderia e seria causa sy asy oviese a pasar quel dicho apartamiento non fuese firme nin los judios de la dicha aljama esto mismo apartados de los christianos segund las leyes por nos fechas en la çibdad de Toledo lo disponen. E allende desto dis que se les podria recresçer peligro e danno. E asymismo dis que los dichos canonigos de la dicha iglesia fisieron poner e pusieron un cruçifixo a la puerta de un corral de la dicha iglesia que sale a la voca de la dicha juderia, lo qual dis que fue con ynteçion de les buscar achaques e calunias e perjudicar e dannar la dicha juderia, en lo qual dis que todos los judios e de la dicha aljama resçebien grand agravio e danno. E nos suplicaron e pedieron por merçed que sobre ello les proviesemos de remedio con justicia como la nuestra merçed fuese, mandando çerrar la dicha puerta e quitar la dicha ymagen e crucifixo de la dicha puerta de fuera pues es a la puerta e voca de la dicha juderia. Y si lo quisieran poner, que lo pongan dentro a la puerta de la dicha iglesia e non en el corral della, pues nunca avia estado alli y se avia puesto por la dicha cabsa ${ }^{52}$.

A la vista de lo expuesto, los monarcas ordenaban a sus oficiales que si efectivamente la puerta abierta se encontraba dentro de la judería, se cerrara. En el asunto más delicado del crucifijo dispusieron, con evidente diplomacia, que

\footnotetext{
${ }^{52}$ Archivo General de Simancas, Registro General del Sello, 16-VI-1485 (Córdoba), fol. 34 .
} 
sy fallardes que [la imagen] fue puesta maliçiosamente, asymismo proveays en ello como cumple a servicio de Dios e al bien de la dicha çibdad, de manera que ninguna de las partes non resçiba agravio ${ }^{53}$.

La abadía de Párraces mantuvo la propiedad de la iglesia y del conjunto de sus posesiones exactamente durante ciento cincuenta años, hasta 1571 cuando el monasterio de San Lorenzo de El Escorial, al que unos años antes había sido anexionado el cenobio, vendió «la casa que dizen del Corpus Christi con los edificios y mejoramientos que se avían hecho en la iglesia della e con todos sus derechos e pertenencias» ${ }^{54}$. Los compradores y promotores de la operación fueron Manuel del Sello, su hermano Antonio y la mujer de éste, Juana de Tapia, que deseaban establecer en la iglesia y sus dependencias un convento de religiosas clarisas donde pudieran acogerse aquellas mujeres «arrepentidas del pecado público» ${ }^{55}$.

El nuevo convento mantuvo desde su fundación una existencia sin incidencias dignas de mención hasta el siglo XIX, cuando las sucesivas exclaustraciones provocaron un largo período de penurias a las religiosas y supusieron seria amenaza para la conservación del templo ${ }^{56}$. A fines de siglo un hecho fortuito vino a echar por tierra todos los esfuerzos que se habían realizado durante aquellos difíciles años para conservar la antigua sinagoga. La noche del 2 de agosto de 1899 un incendio destruyó por completo el templo, del que sólo quedaron en pie los muros maestros ${ }^{57}$. La respuesta de la sociedad segoviana a este desastre permitió acometer una reconstrucción, ciertamente poco afortunada, que culminó tres años más tarde con el regreso de la comunidad religiosa a su convento ${ }^{58}$.

\footnotetext{
${ }^{53}$ Los reyes encargaron el cumplimiento de estos mandatos al provisor y capellán regio Juan Daza y al contino de la casa real Diego de Carvajal. En ausencia de ambos debía hacerse cargo del asunto el prior del monasterio jerónimo de Santa María del Parral de Segovia.

${ }^{54}$ Ruiz Hernando, El barrio de la aljama hebrea (2008), 130-131.

${ }^{55}$ Colmenares, Historia de la insigne ciudad de Segovia, XLV-III, 566-567. En Archivo Histórico Nacional, Clero, libro 12449, se conservan los estatutos de la nueva comunidad y diversos documentos relativos a la dotación económica del convento.

${ }^{56}$ Ruiz Hernando, El barrio de la aljama hebrea (2008), 132-134. Una completa visión de este conflictivo período en M. BARrio Gozalo, Segovia, ciudad conventual. El clero regular al final del Antiguo Régimen (1768-1836) (Valladolid 1995).

${ }^{57}$ Castellarnau, «La sinagoga Mayor de Segovia», 319-330.

${ }^{58}$ Ruiz HeRnANDo, El barrio de la aljama hebrea (2008), 134-140. En la nueva reforma de 2004, se recrearon elementos decorativos originales de la antigua sinagoga.
} 


\section{LA GESTIÓN ECONÓMICA DE LOS BIENES DE CORPUS CHRISTI}

Aunque la ciudad de Segovia se encontraba fuera del área de influencia de Párraces, la abadía, como ya se ha indicado, mantenía desde el siglo XII una significativa presencia en la sede de la diócesis gracias a la iglesia de San Blas. La posesión de este templo aportaba un indudable prestigio a los canónigos parracenses pero, por lo que sabemos, San Blas no sólo no constituía una fuente de ingresos para la abadía sino que obligaba a ésta a realizar un aporte económico para garantizar su mantenimiento ${ }^{59}$.

De este modo, cuando Párraces aceptó en 1421 la posesión de la iglesia de Corpus Christi con sus casas y solares tenía una larga experiencia en lo que suponía la administración de una propiedad prestigiosa pero carente de rentabilidad económica y alejada además de la propia abadía ${ }^{60}$. No es probable, por tanto, que los canónigos parracenses se hicieran grandes ilusiones sobre los beneficios materiales que pudieran proporcionarles sus nuevas propiedades en la sede de la diócesis. A este respecto poco se puede añadir a lo indicado por Enrique Gavilán, gran conocedor de la economía parracense durante la Edad Media: «Otro aspecto de la marginalidad que en el patrimonio de la abadía representan estas casas se expresa en la renuencia de Párraces a invertir en ellas lo más mínimo [...]. Otro signo de su marginalidad es el hecho de que la gestión y el beneficio sea compartido por las mesas abacial y conventual, en lugar de asignarse a una o a otra; el reparto fue la medida que se adoptó con las partes del patrimonio de gestión más problemática» ${ }^{61}$.

Inicialmente el propio abad de Párraces se hizo cargo de la iglesia, probablemente por la relevancia eclesiástica y social de la anexión. En efecto, en 1424 el abad Juan era «administrador de la iglesia de Corpus

\footnotetext{
${ }^{59}$ Como indicaba un monje de San Lorenzo de El Escorial a mediados del siglo XVII: «Y parece ponía Párraces clérigo que la sirviese y le daba de salario todo lo que ella rentaba. Y porque era muy poco, le daba ciertos maravedís. Y los ponía éstos de más por sustentar aquella iglesia, que ya que no les rentaba nada, antes ponía dineros, por sola la jurisdicción que en ella tenía a vista del ordinario de Segovia la sustentaba y tenía en pie y le era de grande autoridad», ANÓNIMO, «La abadía de Párraces», 184.

${ }^{60}$ La abadía de Párraces, actualmente de propiedad particular, se encuentra en el término municipal de Bercial, a $32 \mathrm{~km}$ de Segovia.

${ }^{61}$ Gavilán, El dominio de Párraces, 320.
} 
Christi de la dicha çibdad, della e de sus bienes muebles e rayses», al tiempo que Juan Sánchez y Pedro Sánchez eran capellanes del templo $^{62}$. Diez años más tarde, en 1434 y de ahí en adelante, encontramos sin embargo a un rector al frente de la iglesia, en este caso el canónigo parracense Juan García ${ }^{63}$. Por lo que respecta a la propia iglesia y a sus posesiones, en 1478 se menciona al conjunto como una granja de la abadía $^{64}$.

La documentación refleja con bastante claridad las dificultades económicas por las que Corpus atravesó desde el principio. En 1422, sólo un año después de haber tomado posesión del templo, la abadía recibió también del obispo Juan Vázquez el monasterio de San Pedro de las Dueñas. El prelado estipuló en esta nueva donación que de las rentas del monasterio de San Pedro se destinaran cincuenta fanegas anuales de trigo y otras tantas de cebada a la iglesia de Corpus ${ }^{65}$. Esta disposición del obispo demuestra tanto su implicación personal con el templo como la necesidad que éste tenía de recursos para su mantenimiento. Cinco décadas más tarde, en 1469, el papa Pablo II autorizó la anexión a Corpus del beneficio de la iglesia parroquial de Martín Miguel, para que sus rentas se aplicaran «ad reparationem, manutentionem et conservationem edificiorum, structurarum et ornamentorum» ${ }^{66}$. Al año siguiente, en 1470, los canónigos reconocían con descarnada sinceridad al ceder un solar en censo que éste «ha mas de çinquenta annos que no ha rentado, ni agora renta cosa alguna» ${ }^{67}$. Medio siglo era precisamente el tiempo que la abadía llevaba en posesión de dicho solar.

\footnotetext{
${ }^{62}$ AGP, Patronatos, San Lorenzo, leg. 85-2 (10-V-1424, Segovia).

${ }^{63}$ ACS, F-53 (11-IV-1434, abadía de Párraces, traslado de 6-XII-1440, Segovia).

${ }^{64}$ AGP, Patronatos, San Lorenzo, leg. 85-1 (contrato de Mayr de Vidas), fol. 1r.

${ }^{65}$ GaVILÁn, El dominio de Párraces, 83.

${ }^{66}$ AGP, Patronatos, San Lorenzo, leg. 1682. S. Simonsohn, The Apostolic See and the Jews. Vol. III. Documents: 1464-1521 (Toronto 1990), 1160-1163 (doc. 930: 20-V-1469, Roma), edita el registro de este documento conservado en el Archivio Segreto Vaticano (Registri Vaticani, 533, fol. 200r-v).

${ }^{67}$ AGP, Patronatos, San Lorenzo, leg. 85-1. Al citar una casa lindera al solar se indica que aquella era también propiedad de Párraces, pero no se ofrece ninguna otra referencia, indicio quizá de que en aquel momento la vivienda se encontraba deshabitada y sin inquilinos.
} 


\section{Casas y SOlares Pertenecientes A la SinAgoga Mayor}

Actualmente, si es que alguna vez la hubo, no se conserva ninguna relación de los bienes y propiedades pertenecientes a la sinagoga Mayor que fueron entregados por el obispo de Segovia a los canónigos de Párraces en 1421. Tan solo tenemos constancia, como ya se ha visto, de que el prelado les cedió la propiedad de la iglesia de Corpus Christi «con todas las cosas, casas e solares que oy en dia le pertenesçen e pertenesçer deven en qualquier manera, con todas sus entradas e salidas e corrales, sobrados altos e baxos, qualesquier que sean, enfiestos o derribados» ${ }^{68}$. Por fortuna esta ausencia de noticias puede subsanarse con los datos proporcionados por seis contratos de arrendamiento de casas y solares efectuados por la abadía de Párraces entre los años 1424 y 1478. Los inmuebles objeto de esos contratos son, sin duda alguna, las «casas e solares» que recibieron los canónigos parracenses junto con la iglesia de Corpus, lo que permite reconstruir, aunque sea a posteriori y probablemente de un modo incompleto, el conjunto de las propiedades inmobiliarias que conformaron en su momento el patrimonio de la sinagoga Mayor.

\subsection{Los contratos de arrendamiento (1424-1478)}

Aunque sólo se han conservado los seis contratos de arrendamiento de los bienes de Corpus ya mencionados, éstos permiten seguir a grandes rasgos la evolución del patrimonio durante medio siglo y fijar con precisión la situación del mismo entre 1470 y 1478. A continuación paso a detallar el contenido de cada uno de los censos, ofreciendo para su mejor comprensión la traslación de sus datos al callejero actual.

En 1424 Ferrán Arias tomaba en censo enfitéutico de la abadía por cien maravedís anuales «unas casas que la dicha iglesia han, que son çerca de la puerta de la dicha iglesia, de que son linderos de la una parte casas de mi el dicho Ferrant Arias e de la otra parte casas de [en blanco] e delante la puerta la calle publica del rey que va a la juderia de la dicha çibdat» ${ }^{69}$. Los linderos que recoge este contrato no permiten situar con

\footnotetext{
${ }^{68}$ AGP, Patronatos, San Lorenzo, caja 49, exp. 38.

${ }^{69}$ AGP, Patronatos, San Lorenzo, leg. 85-2 (10-V-1424, Segovia).
} 
precisión la ubicación del inmueble, pues la única referencia reconocible es la «calle publica del rey que va a la juderia», correspondiente a la actual de la Judería Vieja.

Cinco décadas después, en 1470, la abadía entregaba también en censo enfitéutico al joyero judío Abraham Lumbroso por mil maravedís y cuatro gallinas anuales un «solar a la juderia çerca de la iglesia de Corpus Christi, el qual tiene derrocadas todas las paredes ${ }^{70}$. Una de las cláusulas del contrato obligaba al joyero a edificar una casa en el solar y especificaba detalladamente las condiciones de la obra ${ }^{71}$. El solar, sobre el que ocho años más tarde consta que ya se levantaba la casa ${ }^{72}$, corresponde a la mitad izquierda del actual $n^{\circ} 16$ de la calle de la Judería Vieja, siendo los linderos que recoge el contrato de 1470 los siguientes: por delante «la calle publica que viene de la calle del Puerco e va al canno de la Juderia» (calle de la Judería Vieja), por la izquierda «casas de Corpus Christi» (casa $\mathrm{n}^{\circ} 18$ de la calle Judería Vieja), y por la derecha, la «calle que deçiende de la juderia e va derecha al postigo de la juderia de la çerca» (calle de la Puerta del Sol).

El año 1474 los canónigos llevaron a cabo una inusual operación que supuso la primera enajenación documentada de una de las propiedades pertenecientes a Corpus. En fecha desconocida, Frayme de Vidas tomaba en censo una de las casas de Corpus, situada «quasy enfruente de la

\footnotetext{
${ }^{70}$ AGP, Patronatos, San Lorenzo, leg. 85-1 (20-XI-1470, abadía de Párraces). Abraham Lumbroso figura en el registro de pitanzas de 1478-79 alquilando a la catedral unas casas en el entorno de la puerta de San Martín por cuatrocientos maravedís (ACS, C-449, fol. $12 r$ ), casas que debieron ser usadas por él como tienda o taller, no como vivienda, pues mantuvo el arrendamiento después de 1481, una vez establecida la judería (ACS, C-450, pitanzas 1481-82, fol. 11r).

${ }^{71}$ «[...] con postura e conveniençia que vos el dicho Abraham Lunbroso fagades e hedefiquedes de edefiçios en este dicho solar desde la calle real fasta en cabo del dicho solar que es entre el dicho solar e las casas en que bive don Baru tornero, esto se entienda en la pared de abaxo. E çerca de las aguas que caen en el dicho solar de las casas en que mora el dicho don Baru, que vos el dicho don Abraham a vuestra costa debolvades e echedes a la calle real e al patyn de Corpus Christi, de manera que sobre el dicho solar nin en el non ayan mas de caer nin cayan las dichas aguas [...]».

${ }^{72}$ En el contrato realizado en 1478 por Mayr de Vidas se cita como lindero derecho «casas en que mora Abrahan Lunbroso que son del dicho monesterio e yglesia de Corpus Christi», lo que indica que donde en 1470 había un solar, en 1478 ya había una casa (AGP, Patronatos, San Lorenzo, leg. 85-1).
} 
yglesia», por cien maravedís anuales ${ }^{73}$. Tras su muerte, su hijo rabí Abibe de Vidas, heredero del censo, proponía a Párraces que se le eximiera del pago de la renta y se le entregara la libre propiedad de la casa, ofreciendo a cambio un censo anual de doscientos maravedís, el doble de lo que pagaba hasta ese momento, sobre una casa situada junto a la cercana puerta de San Andrés cuyo propietario era Abraham Navarro. La participación de Navarro en esta operación a tres bandas, que le habría de convertir en censatario de Párraces, la explicaba él mismo indicando «que el oviera resçebido e resçibiera çierta quantia de maravedis del dicho raby Habibe, judio, fijo de don Frayme de Vidas, por rason que el resçibiese sobre las dichas sus casas pensyon, tributo, censo e canon de dosientos maravedis en cada un anno» ${ }^{74}$.

La última operación relativa a las casas de Corpus de la que tenemos noticia es la efectuada en 1478 a instancias de otros dos judíos, Mayr de Vidas y Salomón Abentistiel. Éstos tenían arrendadas en censo vitalicio «quatro pares de casas» por las que pagaban cinco mil maravedís anuales, cuando decidieron ofertar a la abadía un aumento de seiscientos maravedís sobre esta renta a cambio de que el censo se convirtiera en enfitéutico, o perpetuo, y de que, junto a ellos, se integrara como censatario el mercader Frayme de Vidas. Los canónigos de Párraces hicieron poner «çedulas en las puertas de la yglesia de Sant Miguell et en las puertas de Sant Martin» para publicitar la oferta recibida, pero «nunca se fallo persona alguna que tanto diese nin mas que los dichos judios», de modo que finalmente aceptaron la propuesta. Los tres nuevos contratos se firmaron, en las condiciones señaladas, el 6 de abril de 1478 en la misma iglesia de Corpus Christi ${ }^{75}$.

\footnotetext{
${ }^{73}$ La aparente coincidencia de su situación, «çerca de la puerta de la dicha iglesia» (1424) y «quasy enfruente de la yglesia» (1474), la cesión con el mismo tipo de censo, enfitéutico, y la exacta correspondencia de la renta, cien maravedís, me llevan a pensar que este inmueble quizá fuera el arrendado por Ferrán Arias cincuenta años atrás. Curiosamente, en ambos casos resulta imposible ofrecer la ubicación exacta de la casa al no recoger los contratos los linderos correspondientes.

${ }^{74}$ AGP, Patronatos, San Lorenzo, leg. 85-1 (28-XI-1474, abadía de Párraces).

${ }^{75}$ AGP, Patronatos, San Lorenzo, legs. 85-1 (contratos de Mayr y Frayme de Vidas) y 157-1 (contrato de Salomón Abentistiel). La información que ofrecen estos tres documentos sobre los judíos que habitaban en el entorno de la iglesia se puede completar con los datos proporcionados por el registro de la mayordomía de pitanzas de 1478-79 (ACS, C-449, fols. 11v-12r).
} 
En cuanto a la valoración de esta operación, que afectó a la práctica totalidad de los inmuebles de Corpus administrados por la abadía, poco se puede añadir a lo indicado por el ya citado Enrique Gavilán: «que sólo un $10 \%$ de mejora en la pensión satisfaga a los canónigos al convertir en enfitéutico un censo de por vida es muy expresivo del pesimismo con el que contemplaban las expectativas de rentabilidad de sus casas en la ciudad» ${ }^{76}$.

Por lo que respecta a Mayr de Vidas, tomó en censo la casa en la que vivía y otra donde residía Isaac Abenforna, hijo de Abraham Abenforna ${ }^{77}$. Esta casa corresponde al actual $\mathrm{n}^{\circ} 18$ de la calle de la Judería Vieja, siendo sus linderos, por delante «la calle del Rey» (calle de la Judería Vieja); por detrás «patin e corral de la dicha yglesia de Corpus Christi»; por la izquierda «casas en que mora Mose Soef» (casa n ${ }^{\circ} 20$ de la calle Judería Vieja); y por la derecha «casas en que mora Abraham Lunbroso que son del dicho monesterio e yglesia de Corpus Christi» (mitad izquierda de la casa $n^{\circ} 16$ de la calle Judería Vieja).

En segundo lugar, Frayme de Vidas recibió en arrendamiento la casa donde vivía Mosé Soef ${ }^{78}$. Este inmueble corresponde al actual no 20 de la calle de la Judería Vieja, siendo sus linderos los siguientes: por delante «la calle publica del Rey» (calle de la Judería Vieja); por detrás, «patyn e corral de la dicha yglesia de Corpus Christi»; por la izquierda, la «casa de Salamon Abentistiel en que mora Mose Fari e donna Azebuena» (la mitad derecha de la casa $\mathrm{n}^{\circ} 8$ de la plaza de Corpus Christi); y por la derecha, «casa de don Mayr de Vidas en que mora agora don Çag Abenforna» (casa ${ }^{\circ} 18$ de la calle Judería Vieja).

Por último, Salomón Abentistiel tomó en censo dos casas, una en la que residía él mismo y otra en la que vivían «Mose ¿Fari? ${ }^{79}$ e donna

\footnotetext{
${ }^{76}$ GaVILÁn, El dominio de Párraces, 320. Hay que matizar que la mejora fue exactamente del $12 \%$. Un acercamiento sencillo y conciso a la cuestión censual en A. Ballester Martínez, «Los censos: concepto y naturaleza», Espacio, Tiempo y Forma. Serie IV. Historia moderna 18-19 (2005-2006), 35-50.

${ }^{77}$ AGP, Patronatos, San Lorenzo, leg. 85-1 (6-IV-1478, Segovia).

${ }^{78}$ AGP, Patronatos, San Lorenzo, leg. 85-1 (6-IV-1478, Segovia).

${ }^{79}$ El escribano cita en el texto a Mosé Soef, pero, de acuerdo con el contrato firmado por Frayme de Vidas, debería figurar Mosé Farí. Da la sensación de que el escribano dejó espacio para el nombre de familia, que rellenó finalmente poniendo Soef.
} 
Azybuena» ${ }^{80}$. Este inmueble se corresponde con la mitad derecha del $\mathrm{n}^{\circ} 8$ de la calle de la Judería Vieja, siendo sus linderos los siguientes: por delante, «la calle del Rey» (calle de la Judería Vieja); por la izquierda, «casas de raby Mose Abenmayor que tyene en çense perpetuo feteosyn de los dichos sennores administrador, prior, canonigos e convento de Parrases» (la otra parte de la casa $\mathrm{n}^{\circ} 8$ ); y por la derecha, «casa en que mora Mose ¿Soef?» ${ }^{81}$ (casa $n^{\circ} 20$ de la calle de la Judería Vieja).

Los tres arrendadores, Mayr, Frayme y Salomón, recibieron los inmuebles con las mismas condiciones, marcadas en sus aspectos arquitectónicos por la cercanía a la iglesia de Corpus ${ }^{82}$.

\footnotetext{
${ }^{80}$ AGP, Patronatos, San Lorenzo, leg. 157-1 (6-IV-1478, Segovia).

${ }^{81}$ El escribano cita en el documento a Mosé Saer pero, de acuerdo con el contrato firmado por Frayme de Vidas, debería figurar Mosé Soef.

${ }^{82}$ «Otrosy le dieron las dichas casas e cada una dellas con tal postura e condiçion que desde oy dia de la fecha desta carta fasta el mes de mayo primero que verna e desde el dicho mes de mayo en un anno, el dicho don Mayr e la dicha su muger e fijos e herederos e subçesores fuese e fuesen tenudos e obligados a labrar las paredes de las dichas casas que salen a la parte del patin e corral de la dicha yglesia de Corpus Christi desde el suelo fasta el thejado de las dichas casas de tapias nuevas con su hormigo de cal e con sus pilares de ladrillo con su cal, de la manera que estan fechas las tappias de rabi Mose Abenmayor [...]. Otrosy le dieron las dichas casas e cada una dellas con tal postura e condiçion que non pudiese tener nin toviesen ventanas algunas fasia la dicha iglesia, corral e patyn della salvo las lumbreras de la anchura que pueden ser dos manos ayuntadas en ancho, e puesto en cada una dellas un baston de fierro en medio de la tal lumbrera por que non pueda caber cabeça de persona alguna para mirar a la dicha yglesia nin echar por ellas cosa de aguas nin de otra cosa alguna. Et sy se oviere de faser alguna ventana, que se ponga en ella una red de fierro espesa a vista e consentimiento de los dichos sennores administrador, prior, canonigos e convento del dicho monasterio o de qualquier dellos o de quien su poder oviere. Et que las dichas lumbreras et ventanas que se fagan altas del suelo de las camaras o sobrados, que non puedan mirar a la dicha yglesia et casas de Corpus Christi. Otrosy que a la parte de la dicha yglesia en lo baxo que non podiese faser nin fisiese ventana nin lumbrera alguna que pase a ninguna bodega de la dicha casa. Et que la mas baxa lumbrera que se oviere de faser en la dicha pared que fuese e sea de estado e medio en alto del suelo de las dichas casas de la parte del suelo del dicho patyn e corral de la dicha yglesia. Et todo esto a vista e consentimiento del dicho Alfonso Peres de Toledo», AGP, Patronatos, San Lorenzo, leg. 85-1 (contrato de Mayr de Vidas), fol. 10r-v. En el caso del citado Mayr, le concedieron una licencia particular: «Otrosy, que non obstante todo lo susodicho, que davan e dieron lugar al dicho don Mayr de Vidas que pudiese faser e fisiese una lumbrera pequenna para su bodega baxa con su red de fierro detras del canton que esta en la casa del dicho don Mayr» (fol. 10v).
} 
5.2. Propuesta de reconstrucción de las propiedades de la sinagoga Mayor

La parcela del solar urbano donde se situaba la antigua sinagoga Mayor no ha sufrido modificaciones significativas desde la Edad Media. El espacio se encuentra delimitado por la muralla, por dos estrechas calles,

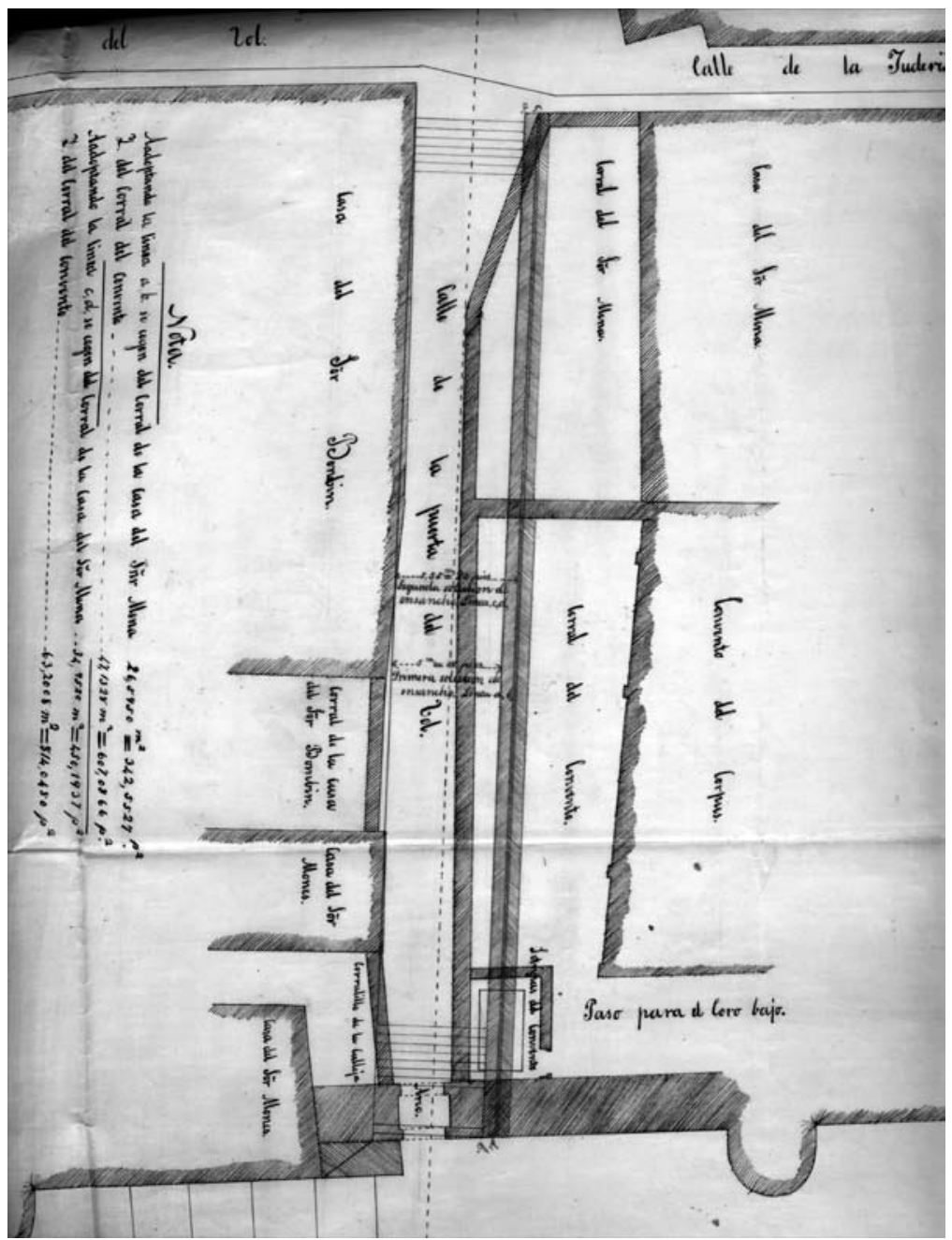

Figura 3: Proyecto de ensanche y alineación de la calle de la Puerta del Sol. Nicomedes Perier. Año 1868 (Archivo Municipal de Segovia, 319-28). 
la de la Puerta del Sol y la de la Judería Vieja, y por las viviendas que continúan la manzana (figura 4). El cambio más destacable experimentado en esta zona fue el ensanche y la alineación de la calle de la Puerta del Sol proyectado y ejecutado por el arquitecto municipal Nicomedes Perier entre 1868 y $1869^{83}$ (figura 3).

Frente a esta continuidad en la trama urbana, es en el caserío donde se han producido las reformas más importantes desde el siglo XV. Donde en aquellos momentos se situaban patios y corrales, hoy se levantan diversas edificaciones (viviendas $n^{\circ} 3$ y 5 de la calle de la Puerta del Sol, mitad derecha de la $n^{\circ} 16$ de la calle de la Judería Vieja, ampliación de la iglesia de Corpus Christi en sus fachadas norte y sur, y construcción del claustro del convento). Al mismo tiempo, una de las viviendas actuales engloba dos de los inmuebles existentes en aquellos momentos ${ }^{84}$.

Los contratos realizados en 1470 y 1478 permiten obtener una visión muy precisa de la composición y la ubicación de los bienes pertenecientes a la iglesia de Corpus, que no eran otros que los que habían conformado el conjunto de posesiones de la sinagoga Mayor ${ }^{85}$. De este modo, en 1478 la granja de Corpus Christi estaba integrada por la iglesia, centro articulador de todo el conjunto, cinco inmuebles y un solar, que se situaban frente a la fachada norte del templo y discurrían consecutivamente y sin interrupción entre los actuales $\mathrm{n}^{\mathrm{o}} 16$ de la calle de la Judería Vieja y $\mathrm{n}^{\mathrm{o}} 7$ de la plaza de Corpus Christi, y por los patios y corrales pertenecientes tanto a la iglesia como a las casas. Considerando estas viviendas de oeste

\footnotetext{
${ }^{83}$ Archivo Municipal de Segovia, 319-28.

${ }^{84}$ La documentación manejada no me ha permitido encontrar una solución plenamente satisfactoria a esta cuestión. Las plantas actuales de los inmuebles no permiten discernir cual de ellos integró las dos antiguas viviendas y el estudio detenido de las fachadas tampoco aporta evidencias definitivas. En todo caso, la fachada de comienzos del siglo XX del edificio $n^{\circ} 8$ de la plaza de Corpus Christi me lleva a considerar, aunque con muchas dudas, que esta vivienda pudiera ser la que agrupara las dos edificaciones medievales.

${ }^{85}$ Hay un inmueble más, que desde 1474 ya no era propiedad de Párraces pero que se debe mencionar por tratarse de uno de los pertenecientes originalmente a la sinagoga Mayor. Se trata de la vivienda correspondiente a los censos de 1424 y 1474 (ver nota 73). Se desconoce la ubicación exacta de esta casa, pero es significativo el hecho de que no aparezca citada en los linderos de los inmuebles arrendados en 1470 y 1478, lo que indica que, aunque cercana, no se integraba en el conjunto que se extendía frente la fachada norte de la iglesia.
} 


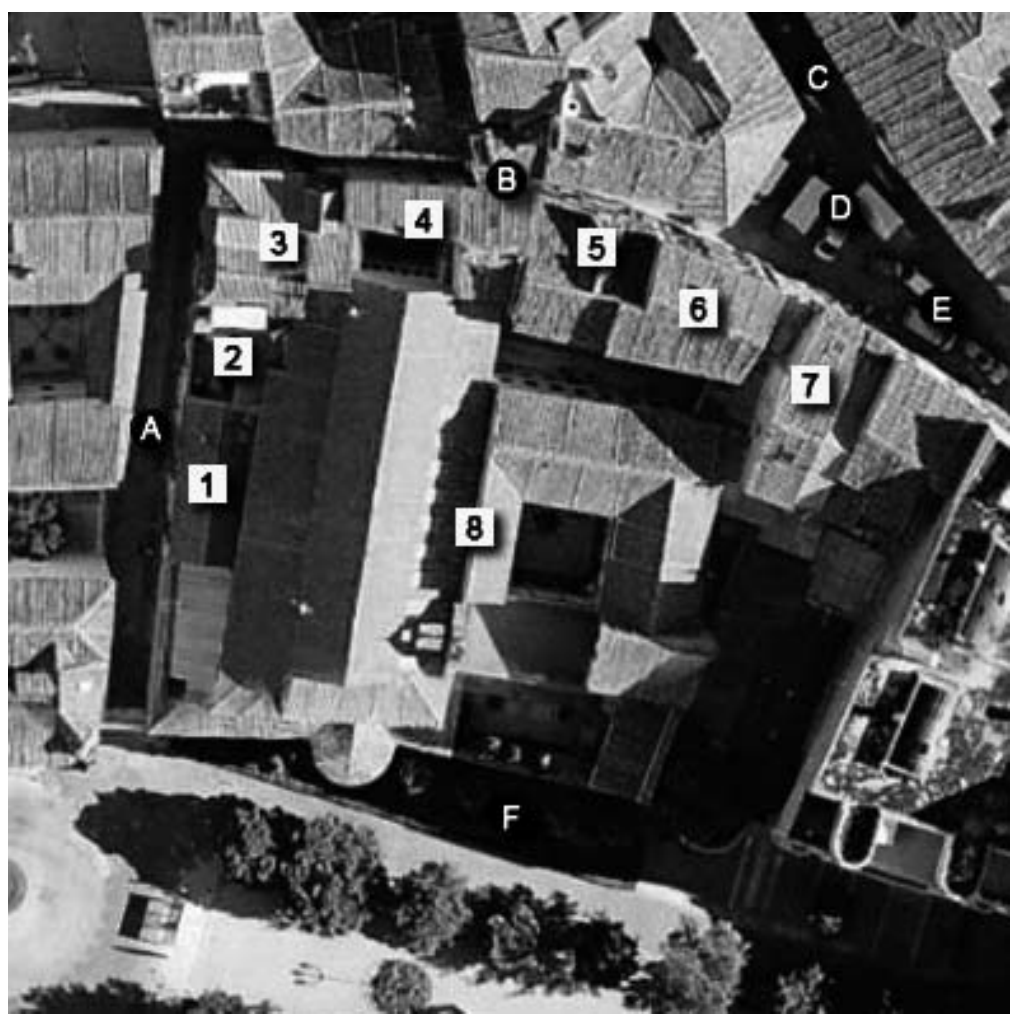
A. Calle de la Puerta del Sol
B. Calle de la Judería Vieja
C. Calle de Isabel la Católica
D. Plaza de Corpus Christi
E. Calle de Juan Bravo
F. Muralla

1. Calle de la Puerta del Sol no 5

2. Calle de la Puerta del Sol no 3

3. Calle de la Judería Vieja $n^{\circ} 16$

4. Calle de la Judería Vieja no 18

5. Calle de la Judería Vieja $n^{\circ} 20$

6. Plaza de Corpus Christi $n^{\circ} 8$

7. Plaza de Corpus Christi n ${ }^{\circ} 6$

8. Plaza de Corpus Christi $n^{\circ} 7$

(Convento de Corpus Christi)

FIgURA 4: Estado actual del entorno de la iglesia de Corpus Christi. 


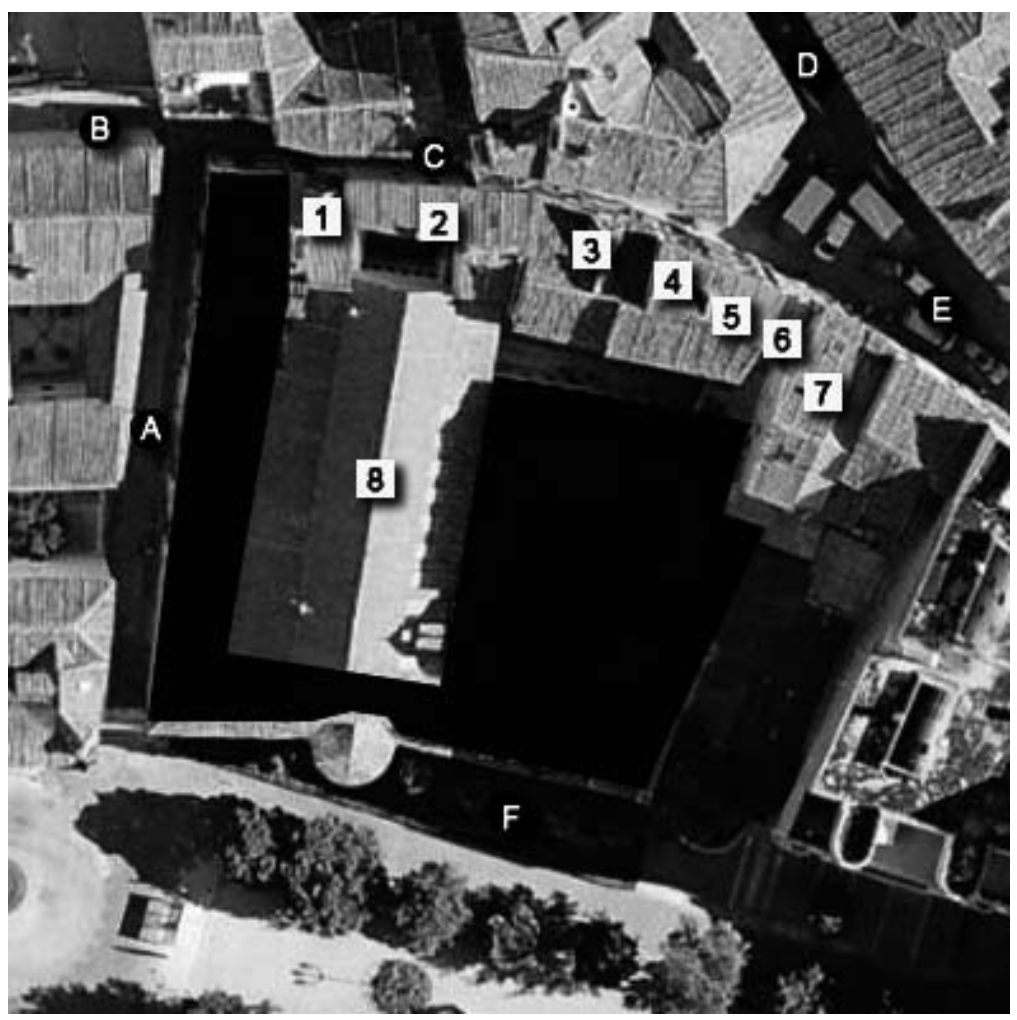
A. Calle que va al postigo de la judería
B. Calle que va al caño de la judería
C. Calle pública del rey
D. Calle de la Zapatería o de la Cintería
E. Calle del Puerco
F. Muralla

1. Casa arrendada al joyero Abraham Lumbroso

2. Casa arrendada a Mayr de Vidas

3. Casa arrendada al mercader Frayme de Vidas

4. Casa arrendada a Salomón Abentistiel

5. Casa arrendada a rabí Moisés Abenmayor

6. Solar. Puerta de acceso al patio de la iglesia de Corpus Christi

7. Casa del boticario Juan de Segovia

8. Iglesia de Corpus Christi

FiguRa 5: Reconstrucción del entorno de la iglesia de Corpus Christi en 1478 (la zona sombreada corresponde a patios y corrales en la época). 
a este, las mismas estaban ocupadas en aquellos momentos por el joyero Abraham Lumbroso, por Mayr de Vidas e Isaac Abenforna, por Moisés Soef ${ }^{86}$, por Salomón Abentistiel, por Moisés Fari y doña Azebuena, y, en último lugar, por rabí Moisés Abenmayor. A continuación se encontraba el solar donde se situó la actual puerta de entrada al patio de la iglesia, propiedad también de la abadía de Párraces. Marcaba el límite de todo este conjunto la casa del boticario Juan de Segovia, ajena ya a las posesiones canonicales (ver figura 5).

La sinagoga Mayor de Segovia sigue siendo todavía una ilustre desconocida. Nada sabemos, fuera de su misma presencia, del verdadero significado que tuvo para los judíos de Segovia durante su, sospecho que breve, existencia. La expropiación de la sinagoga y su consagración como iglesia supuso, como no es necesario explicar, un cambio radical en su naturaleza y en sus funciones pero, como se ha podido ver, la articulación económica del nuevo templo se atuvo estrictamente a las bases creadas durante la etapa sinagogal. Esta circunstancia permite que un pequeño número de documentos de naturaleza eminentemente administrativa, fechados medio siglo después de la expropiación, permitan acercarse, aunque sea retrospectivamente, a una de las realidades que conformaron la existencia de la sinagoga Mayor, la de su dotación económica ${ }^{87}$.

\footnotetext{
${ }^{86}$ Éste es el único caso en el que el poseedor del censo, Frayme de Vidas, no residía en el inmueble.

${ }^{87}$ Este trabajo forma parte del proyecto de investigación del Ministerio de Ciencia e Innovación «Legitimación del poder, corrientes religiosas y prácticas de piedad en la corona de Castilla, siglos XII-XV» (HAR2008-04696/HIST). Quiero expresar mi agradecimiento a Antonio Ruiz, Rafael Cantalejo, Javier Martín (Jams), Ignacio Hernández y Álvaro Hernández por la inestimable ayuda que me han prestado en la realización de este artículo.
} 


\section{APÉNDICE}

\section{1}

1421, noviembre, 25, Turégano

El obispo segoviano Juan Vázquez anexiona la iglesia de Corpus Christi, antigua sinagoga Mayor de Segovia, a la abadía agustina de Santa María de Párraces, estableciendo que si en el futuro decide fundar allí un hospital, éste deberá ser atendido por los canónigos de la abadía.

Archivo General de Palacio, Patronatos, San Lorenzo, caja 49, exp. 38 (Traslado, 4-XI-1438, Segovia. Papel, 2 hojas, 221 x $148 \mathrm{~mm}$ ).

Reg. Conrado Morterero Simón, «La abadía de Santa María de Párraces», en IV Centenario de la fundación del monasterio de San Lorenzo el Real. El Escorial 1563-1963. II. Arquitectura, Artes (Madrid 1963), 775-776 (doc. 142). Cit. Enrique Gavilán, El dominio de Párraces en el siglo XV. Un estudio sobre la realidad feudal (Zamora 1986), 82 y 319; José Antonio Ruiz Hernando, El barrio de la aljama hebrea de Segovia (Segovia 2008), 123.

Don Juan, por la gracia de Dios e de la Santa Eglesia de Roma obispo de Segovia, por faser bien, merçed e limosna a vos, don Juan, abad del monesterio de Santa Maria de Parrases que agora sodes e a los otros abades vuestros subçesores que despues de vos fueren e a cada uno dellos e a los religiosos que agora son e seran de aqui adelante en el convento del dicho monesterio, damos vos canoniçe e fasemos vos merçed perpetua para agora e para sienpre jamas de la eglesia nueva de Corpore Christi que es en la çibdat de la dicha Segovia, la qual fue signoga de los judios, con todas las cosas, casas e solares que oy en dia le pertenesçen e pertenesçer deven en qualquier manera, con todas sus entradas e salidas e corrales, sobrados, altos e baxos, qualesquier que sean, enfiestos o derribados, que a la dicha eglesia pertenescan e pertenesçer devan asi de fecho como de derecho, dando vos licençia e abtoridat para que podades çelebrar e faser çelebrar e desir en la dicha eglesia los ofiçios divynales cada que quesierdes e por bien tovierdes, e para que podades reparar e refaser los hedefiçios de la dicha eglesia e usar dellos e en ellos bien, asi como de las otras cosas e hedefiçios que al dicho monesterio pertenesçen e para hedefiçar de nuevo si conpliere cada que quisierdes sin perjuysio de otro alguno, e generalmente para que usedes e podades usar de la dicha eglesia e de todo lo que a ella pertenesçe asi como cosa propia del dicho monesterio.

La qual eglesia con todas sus pertenençias nos anexamos, apropiamos e unimos canoniçe e perpetuo al dicho monesterio de Parrases en la mas larga e mejor forma que de derecho pueda e deva ser anexada, apropiada e unida, dando vos e otorgando vos por esta presente carta la propiedat e posesion real, corporal vel 
quasi de la dicha eglesia de Corpore Christi con todas sus pertenençias como dicho es, reteniendo en nos todavia en la dicha eglesia e en los sus admenistradores nuestra pontifical jurisdiçion, visitaçion e correçion e nuestra devida reverençia.

Otrosi quedando nos sienpre a salvo que si en algund tienpo a nos bien visto fuere en la dicha eglesia o en qualquier de sus casas ordenar o fundar ospital, nos dando doctaçion e sustentaçion conpetente para el, que vos los dichos abat e convento seades obligados a rresçebir en vos la carga e cuydado de la dicha ospitalidat por vos o por persona ydonea, todavia quedando en vos o en vuestros subçesores la guvernaçion e administraçion de qualesquier bienes asi espirituales como tenporales que por nos fueren asignados para sustentaçion e gubernaçion del dicho ospital.

De lo qual todo e cada cosa dello vos mandamos dar esta nuestra carta de anexaçion e union perpetua firmada de nuestro nonbre e sellada con nuestro sello pontifical. Por la qual mandamos en virtud de obediençia e so pena de excomonion a qualquier clerigo o coronado de la dicha çibdat e de todo nuestro obispado que con ella fuere requerido que vos ponga en la posesion corporal, real vel quasi de la dicha eglesia. E puesto, vos defienda en ella. So esa mesma pena, mandamos a qualquier escribano o notario publico de todo nuestro obispado que para esto fuere llamado e requerido, que la lea e la publique e leyda e publicada vos la torne e vos lo de todo signado e tornado en publica forma para guarda e muniçion de vuestro derecho e del dicho vuestro monesterio.

Fecha en la nuestra villa de Toruegano, martes veynte e çinco dias del mes de novienbre anno a nativitate Domini $\mathrm{M}^{\circ} \mathrm{CCCC}^{\circ} \mathrm{XXI}^{\circ}$.

Episcopus Segobiensis.

1424, mayo, 10, Segovia

Ferrán Arias, vecino de Segovia en la parroquia de San Miguel, toma en censo enfitéutico de la abadía agustina de Santa María de Párraces una casa en Segovia junto a la iglesia de Corpus Christi por cien maravedís anuales.

AGP, Patronatos, San Lorenzo, leg. 85-2 (Original múltiple: «et por ruego et otorgamiento de amas las dichas partes escrevi esta carta para el dicho sennor abad». Papel, 387 x $322 \mathrm{~mm}$ ).

Reg. Morterero Simón, «La abadía de Santa María de Párraces», 776 (doc. 166). Cit. Ruiz Hernando, El barrio de la aljama hebrea (2008), 123. 
1470, noviembre, 20, abadía de Santa María de Párraces (Bercial, Segovia)

La abadía de Santa María de Párraces cede en censo enfiteútico al joyero Abraham Lumbroso, vecino de Segovia, un solar en esta ciudad junto a la iglesia de Corpus Christi por mil maravedís y cuatro gallinas anuales. Se insertan dos documentos, la autorización del obispo segoviano Juan Arias Dávila para formalizar el contrato (27-VI-1470, Turégano) y una carta de procuración de Pedro Fernández de Solís, administrador perpetuo de la abadía, en favor del canónigo parracense Juan Fernández de Segovia, del canónigo de la catedral segoviana Fernando González Relojero y de Lope Morquecho (9-VIII-1470, Roma).

AGP, Patronatos, San Lorenzo, leg. 85-1 (Original múltiple: «esta es para el dicho sennor administrador». Pergamino, 8 hojas, 244 x $168 \mathrm{~mm}$ ).

AGP, Patronatos, San Lorenzo, leg. 85-1 (Original múltiple: «esta es para el dicho don Abrahan Lunbroso». Pergamino, 9 hojas, 227 x 157 mm).

Reg. Morterero Simón, «La abadía de Santa María de Párraces», 782 (doc. 339).

Cit. Gavilán, El dominio de Párraces, 320; Ruiz Hernando, El barrio de la aljama hebrea (2008), 238 (nota 113).

4

1474, noviembre, 28, abadía de Santa María de Párraces (Bercial, Segovia)

La abadía de Santa María de Párraces exime a rabí Abibe de Vidas del censo de cien maravedís anuales que paga por una casa en Segovia junto a la iglesia de Corpus Christi y le entrega la libre posesión del inmueble. A cambio, y a instancias del citado Abibe, la abadía recibe un censo anual de doscientos maravedís sobre otra casa situada junto a la puerta de San Andrés y propiedad de Abraham Navarro. Se insertan tres documentos: una comisión del papa Sixto IV al abad de Santa María del Burgo, en Burgohondo, Ávila, y al prior de Santa María del Parral en Segovia para que atiendan los asuntos relativos a la abadía de Párraces y a sus bienes (27-IX-1473, Roma); una carta de procuración de Francisco de Toledo, administrador perpetuo de la abadía, en favor de los citados abad y prior (14-III-1474, Roma); y la autorización del abad y el prior para formalizar el contrato (15-XI-1474, monasterio de Santa María del Parral).

AGP, Patronatos, San Lorenzo, leg. 85-1 (Original múltiple: «e este instrumento es para el dicho monasterio». Papel, 11 hojas, 221 x $154 \mathrm{~mm}$ ).

Reg. Morterero Simón, «La abadía de Santa María de Párraces», 783 (doc. 373). 
1478, abril, 6, iglesia de Corpus Christi (Segovia)

La abadía de Santa María de Párraces cede en censo enfiteútico a Mayr de Vidas, vecino de Segovia, unas casas junto a la iglesia de Corpus Christi en las que viven él mismo e Isaac Abenforna por 2.333 maravedís y dos coronados anuales. Se insertan tres documentos: una carta de procuración de Francisco de Toledo, administrador perpetuo de Párraces, en favor del abad de Santa María del Burgo en Burgohondo, Ávila, y del prior del Parral en Segovia (14-III-1474, Roma); una carta de procuración de la abadía de Párraces en favor del canónigo parracense Juan González de Hoyos y de Alfonso Pérez de Toledo (23-V-1477, abadía de Párraces); y la autorización del abad del Burgo y del prior del Parral para formalizar el contrato (20-X-1477, monasterio del Parral).

AGP, Patronatos, San Lorenzo, leg. 85-1 (Original múltiple: «este instrumento es para los dichos sennores administrador, prior, canonigos e convento del dicho monesterio de Parrases». Papel, 14 hojas, 223 x 157 mm).

Reg. Morterero Simón, «La abadía de Santa María de Párraces», 784 (doc. 395). Cit. Gavilán, El dominio de Párraces, 320; Ruiz Hernando, El barrio de la aljama hebrea (2008), 126.

1478, abril, 6, iglesia de Corpus Christi (Segovia)

La abadía de Santa María de Párraces cede en censo enfiteútico a Frayme de Vidas, mercader y vecino de Segovia, una casa junto a la iglesia de Corpus Christi en la que vive Mosé Soef por 933 maravedís y dos cornados anuales. Se insertan tres documentos: una carta de procuración de Francisco de Toledo, administrador perpetuo de Párraces, en favor del abad de Santa María del Burgo en Burgohondo, Ávila, y del prior del Parral en Segovia (14-III-1474, Roma); una carta de procuración de la abadía de Párraces en favor del canónigo parracense Juan González de Hoyos y de Alfonso Pérez de Toledo (23-V-1477, abadía de Párraces); y la autorización del abad del Burgo y del prior del Parral para formalizar el contrato (20-X-1477, monasterio del Parral).

AGP, Patronatos, San Lorenzo, leg. 85-1 (Original múltiple: «este instrumento es para los dichos sennores administrador, prior, canonigos e convento del dicho monesterio de Santa Maria de Parrases». Papel, 16 hojas, 222 x 154 mm.)

Reg. Morterero Simón, «La abadía de Santa María de Párraces», 784 (doc. 393). Cit. Gavilán, El dominio de Párraces, 320; Ruiz Hernando, El barrio de la aljama hebrea (2008), 126. 
7

1478, abril, 6, iglesia de Corpus Christi (Segovia).

La abadía de Santa María de Párraces cede en censo enfiteútico a Salomón Abentistiel, vecino de Segovia, dos casas junto a la iglesia de Corpus Christi, una en la que vive él mismo y otra donde residen Mosé Farí ${ }^{88}$ y doña Azebuena por 2.333 maravedís y dos cornados anuales. Se insertan tres documentos: una carta de procuración de Francisco de Toledo, administrador perpetuo de Párraces, en favor del abad de Santa María del Burgo en Burgohondo, Ávila, y del prior del Parral en Segovia (14-III-1474, Roma); una carta de procuración de la abadía de Párraces en favor del canónigo parracense Juan González de Hoyos y de Alfonso Pérez de Toledo (23-V-1477, abadía de Santa María de Párraces); y la autorización del abad del Burgo y del prior del Parral para formalizar el contrato (20-X1477, monasterio del Parral).

AGP, Patronatos, San Lorenzo, leg. 157-1 (Original múltiple: «este instrumento es para los dichos sennores administrador, prior, canonigos e convento del dicho monesterio de Parrases». Papel, 16 hojas, 220 x 155 mm).

Reg. Morterero Simón, «La abadía de Santa María de Párraces», 784 (doc. 394). Cit. Gavilán, El dominio de Párraces, 320.

Recibido: $15 / 09 / 2010$

Aceptado: 07/05/2012

\footnotetext{
${ }^{88}$ Ver nota 79.
} 
